\title{
CARACTERIZAÇÃO ECOLÓGICA DE ÁREAS A PARTIR DE DADOS ESPACIAIS PÚBLICOS ESTUDO DE CASO: ÁREA DE COLETA DE SEMENTES
}

\author{
Cátia Augustin ${ }^{1}$, Christel Lingnau ${ }^{2}$, Franklin Galvão ${ }^{3}$, Lucas Pimenta Gonçalves ${ }^{4}$ \\ ${ }^{1}$ Eng $^{\text {a }}$. Florestal, Mestranda em Engenharia Florestal, UFPR, Curitiba, PR, Brasil - catiaraugustin@ gmail.com; \\ ${ }^{2}$ Eng $^{\mathrm{a}}$. Florestal, Dr., Dep. de Ciências Florestais, UFPR, Curitiba, PR, Brasil - lingnau@ufpr.br \\ ${ }^{3}$ Eng. Florestal, Dr., Dep. de Ciências Florestais, UFPR, Curitiba, PR, Brasil - fgalvao@ufpr.br \\ ${ }^{4}$ Eng. Florestal, Mestrando em Engenharia Florestal, UFPR, Curitiba, PR, Brasil - lucaspgoncalves@ hotmail.com
}

Recebido para publicação: 21/11/2011 - Aceito para publicação: 14/07/2012

\begin{abstract}
Resumo
Este estudo procurou avaliar o potencial de uso de dados espaciais públicos, por meio de Sistemas de Informações Geográficas (SIG), na caracterização ecológica de áreas para fins científicos, de preservação ou de produção. O espaço analisado é uma área de coleta de sementes da espécie Phytolacca dioica L., no município de Telêmaco Borba (PR). Os dados empregados estavam disponíveis nos sites de instituições públicas do estado do Paraná. Foram utilizados os mapas: Fitogeográfico, Hidrografia, Uso do solo, Geologia, Degradação, Bacias hidrográficas, Geomorfologia, Solos, Clima e Base Hidrográfica Oficial do Paraná. As árvores matrizes foram georreferenciadas por GPS. A análise espacial gerou o mapa unidades ecológicas, cujo banco de dados permite confeccionar representações dos atributos relacionados. O mapa planialtimétrico do Paraná foi utilizado na composição do modelo digital do terreno e na determinação da altitude, exposição e inclinação da vertente nos pontos onde estão localizadas as matrizes. O uso do SIG foi fundamental para manipular dados e mapas temáticos públicos e mostrou ser concreta a possibilidade de, através deles, não mais se considerar divisões geopolíticas para caracterização de áreas, mas o ambiente em si.

Palavras-chave: Análise espacial; mapas temáticos públicos; unidades ecológicas.
\end{abstract}

\begin{abstract}
Ecological characterization of areas based on public spatial data. Study case: collecting seeds area. This study tried to evaluate the potential use of public spatial data, using Geographic Information Systems - GIS, for ecological areas characterization for scientific, conservation or production purposes. The space in analysis is an area of collecting seeds of Phytolacca dioica L. species, in Telemaco Borba - PR. The spatial data used were available on the websites of public institutions of the Parana state. The maps used in geoprocessing were: Phytogeographical, Hydrography, Land Use, Geology, Degradation, Watershed, Geomorphology, Soils, Climate and Paraná Official Hydrographic Base. The parent trees were georeferenced by GPS. The spatial analysis generated the Ecological Units file, whose database allows for making maps of any related attribute. The planialtimetric map of Paraná was used to make the digital terrain model as well as to determinate elevation, aspect and slope gradient at the points where the parent trees are locate. The use of GIS was basic to available real data and public thematic maps processing and proved the possibility of, through them, no longer considering geopolitical divisions for characterization of areas, but the environment itself.

Keywords: Spatial analysis; public thematic maps; ecological units.
\end{abstract}

\section{INTRODUÇÃO}

A geração acostumada a traçar caminhos pelo Google maps e pelo GPS (Global Positioning System) não imagina o quanto já foi difícil acessar informações espaciais. Até a Idade Moderna, mapas eram bens de família, seus segredos passavam de pai para filho e possuí-los representava poder e perigo. Por ordem do rei de Portugal, na época dos grandes descobrimentos, marinheiros que divulgassem informações sobre as novas regiões eram condenados à morte. Com o passar dos anos, o silêncio foi 
quebrado, e o conjunto das informações armazenadas, graças às novas tecnologias, tornou-se extraordinário. Formidável também é sua possibilidade de uso.

O tempo também deixou sua marca na ecologia. Durante muito tempo, a natureza teve de ser segmentada para poder ser investigada. Mais do que limitações intelectuais, o que obrigava pesquisadores a esse retalhamento era a deficiência tecnológica. $O$ desafio era analisar por partes um todo complexo, formado por porções inter-relacionadas: a geologia e o clima geram o relevo; geologia, clima e relevo determinam o solo; e todos eles somados justificam a vegetação, que por sua vez os modifica no instante mesmo em que se instala.

Hoje já se admite que processos ecológicos são tão ou mais importantes de serem preservados do que espécies. Determinar o que sustenta e possibilita a restauração de formações naturais pode ser imprescindível para conservar desde indivíduos a funções ecológicas de ecossistemas.

A ciência sempre produziu e se beneficiou largamente das representações cartográficas, mas poderia fazê-lo ainda mais. Ferramentas modernas de geoprocessamento, como os Sistemas de Informações Geográficas (SIGs), são capazes de organizar a informação espacial de maneira veloz, precisa e, muitas vezes, barata - quando são usados dados de domínio público. A integração de variáveis que esse tipo de software permite operacionaliza a interdisciplinaridade necessária para a análise ambiental e pode alterar o delineamento de experimentos, aprofundando a discussão dos fenômenos observados. O geoprocessamento, ao organizar computacionalmente os dados geográficos, modifica qualitativamente o tipo de análise possível (CÂMARA; MEDEIROS, 1998).

Este estudo procurou demonstrar o potencial de uso de dados espaciais públicos (leia-se: gratuitos e disponíveis na internet), por meio de SIG, na caracterização ecológica de áreas, seja para fins científicos, seja para preservação ou produção. O espaço aqui analisado é uma área de coleta de sementes da espécie Phytolacca dioica L., no município de Telêmaco Borba, segundo planalto paranaense, região onde está sendo construída, no rio Tibagi, a Usina Hidrelétrica Mauá.

\section{REVISÃO BIBLIOGRÁFICA}

\section{Análise espacial}

Se volume e qualidade de dados são importantes na análise ambiental, as ferramentas que permitem sua manipulação também o são. É o processamento desses dados que vai gerar as informações necessárias para a abordagem que a paisagem exige. Não faz mais nenhum sentido investir tempo e recursos em análises estanques, desvinculadas da dinâmica da natureza.

Assim, SIGs são hoje instrumentos básicos, uma vez que são capazes de armazenar e processar dados georreferenciados, integrando-os e os sintetizando em diferentes escalas e formatos (VEIGA; XAVIER-DA-SILVA, 2004; COSTA; XAVIER-DA-SILVA, 2004).

Dados digitais (cartográficos e alfanuméricos) são, com uma frequência cada vez maior, disponibilizados gratuitamente por instituições públicas e privadas, ao mesmo tempo em que surgem softwares livres ou de baixo custo para sua manipulação. Esse maior acesso às informações permite uma abordagem melhor delineada dos fenômenos naturais, um maior conhecimento do espaço e uma análise mais refinada das relações que aí têm lugar (VEIGA; XAVIER-DA-SILVA, 2004).

\section{Processos ambientais}

$\mathrm{O}$ rigor do clima e a resistência maior ou menor das rochas definem o modelado da paisagem. Nessa região do segundo planalto paranaense, as rochas sedimentares (de origem marinha, lacustre, fluvial e glacial) do Paleozoico são menos resistentes que o diabásio (ígnea básica intrudida durante a abertura do oceano Atlântico) do Mesozoico. Por isso, as regiões mais alçadas correspondem preferencialmente aos diques de diabásio. Como o enxame de diques é admirável nesse local, o relevo é bastante movimentado (MINERAIS DO PARANÁ (MINEROPAR), 2001; MANTESSO NETO et al., 2004; GUIMARÃES et al., 2007).

O solo é o resultado da ação dos agentes do intemperismo sobre as rochas, somada à matéria orgânica depositada e reciclada por plantas, animais, fungos e micro-organismos. Dependendo do tipo de rocha matriz, o solo apresentará predominância de uma de suas frações minerais constituintes: areia, silte ou argila, e quantidades maiores ou menores dessas partículas definem sua principal característica: a textura. A textura influi diretamente na velocidade de infiltração e na capacidade de retenção de água, na 
aeração, na nutrição e na aderência ou força de coesão das partículas do solo (LEPSCH, 2002; SCHAETZL; ANDERSON, 2005).

Nos solos onde a textura arenosa prevalece (solos leves), o teor de areia supera os $70 \%$ e o de argila é inferior a $15 \%$. Estes são solos permeáveis, com baixa capacidade de retenção de água e pouca matéria orgânica. Como são altamente suscetíveis à erosão, exigem cuidados especiais de preparo e conservação. Os solos com textura média têm teores equilibrados de areia, silte e argila. Comumente, apresentam boa drenagem, boa capacidade de retenção de água e são medianamente resistentes à erosão. Para os de textura argilosa (solos pesados), os teores de argila são superiores a 35\%. Esses solos têm baixa permeabilidade e alta capacidade de retenção de água. São mais resistentes à erosão, mas altamente suscetíveis à compactação (EMPRESA BRASILEIRA DE PESQUISA AGROPECUÁRIA (EMBRAPA), 1979; LEPSCH, 2002; EMBRAPA, 2006).

Também a declividade, a altitude e a posição relativa na paisagem, por repercutirem na incidência luminosa, temperatura, vento, precipitação e disponibilidade hídrica, influenciam no desenvolvimento do solo e da vegetação. Dependendo da orientação da face, o terreno receberá maior ou menor radiação e estará exposto a maior ou menor temperatura, mas é a quantidade de água disponível a variável que mais se expressa na vertente. Pode haver diferenças consideráveis do teor de água no solo entre o topo, o meio e a base da encosta, determinando, muitas vezes, inclusive, a topossequência (CHRISTOFOLETTI, 1980; BIGARELLA, 2003; LOPES, 2004).

\section{Espécie}

Phytolacca dioica Linnaeus, Phytolaccaceae, cebolão, ceboleiro, embu, maria-mole ou umbu, na linguagem popular, é uma espécie florestal extremamente plástica. No Brasil, ocorre da Bahia ao Rio Grande do Sul, em altitudes variando de 5 a 1.200 m. Está presente nas Florestas Estacionais Decidual e Semidecidual e nas Ombrófilas Densa e Mista. Espécie pioneira, decídua e predominantemente mésica, ocorre em encostas e planícies aluviais, em solos rasos ou profundos, livres de inundação frequente. A árvore pode atingir $25 \mathrm{~m}$ de altura e $150 \mathrm{~cm}$ de DAP (diâmetro à altura do peito) (REITZ et al., 1983; BACKES; IRGANG, 2002; CARVALHO, 2008).

\section{MATERIAL E MÉTODOS}

A área em estudo está situada no segundo planalto paranaense, município de Telêmaco Borba, na margem direita do rio Tibagi, área de influência da futura Usina Hidrelétrica Mauá (Figura 1). Nessa região, a média histórica de precipitação anual é de $1.608 \mathrm{~mm}$ (INSTITUTO AGRONÔMICO DO ESTADO DO PARANÁ (IAPAR), 2011).

As matrizes de Phytolacca dioica estão dispersas pela região - coordenadas N-S 7.343.668,16 m a 7.321.983,98 m e L-O: $526.504,10 \mathrm{~m}$ a $541.505,80 \mathrm{~m}$ (UTM (Universal Transverse Mercator), SAD (South American Datum) 69, Fuso 22 Sul) - e foram georreferenciadas por meio de GPS (Juno série SB) (Figura 1).

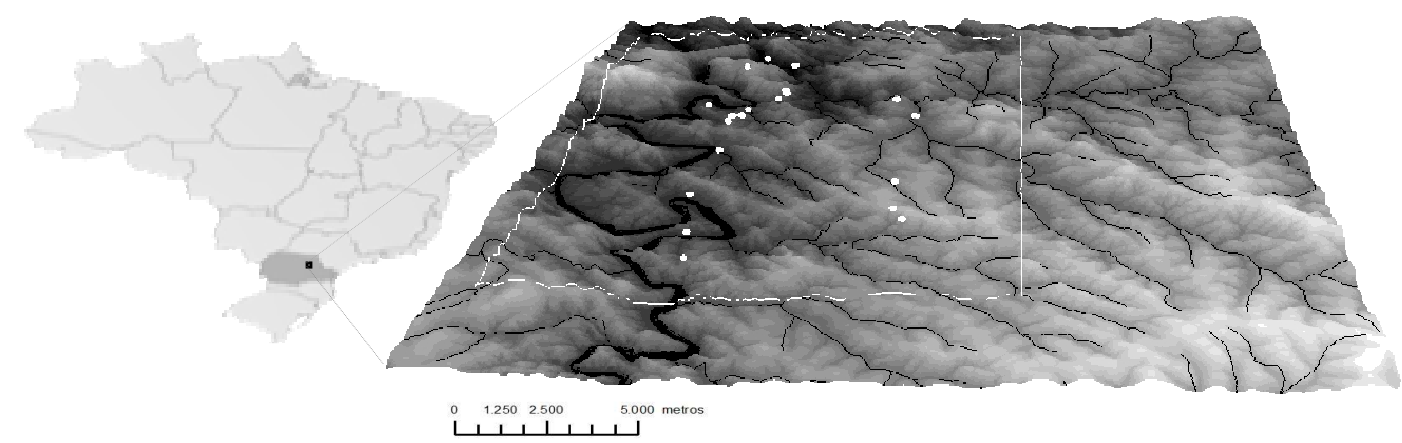

Figura 1. Croqui de localização da área em estudo - Telêmaco Borba, PR, BR (retângulo em branco). Os pontos brancos na representação do terreno correspondem à posição das matrizes.

Figure 1. Focused area location sketch - Telêmaco Borba, PR, BR (white rectangle). The white spots on terrain represent the parent trees position. 
A base cartográfica e os mapas temáticos utilizados para avaliação ecológica são de domínio público (Tabela 1).

Tabela 1. Base cartográfica.

Table 1. Cartographic base.

\begin{tabular}{lcc}
\hline Mapas & Escala & Fonte \\
\hline Geologia & $1: 250.000^{*}$ & MINEROPAR/IPARDES/ITCG* \\
Solos & $1: 600.000^{*}$ & EMBRAPA/EMATER* $^{*}$ \\
Fitogeográfico & $1: 750.000^{*}$ & MAACK/ITCG/IBGE* \\
Uso do solo & $1: 250.000^{*}$ & IPARDES/ITCG, 2001/2002* \\
Degradação & $1: 250.000^{*}$ & SEMA, 1995* \\
Geomorfologia & $1: 250.000^{*}$ & MINEROPAR/IPARDES/ITCG* \\
Bacias hidrográficas & $1: 100.000^{*}$ & SUDERHSA* \\
Hidrografia & $1: 250.000^{*}$ & IPARDES* \\
Clima & $1: 500.000^{*}$ & SIMEPAR* \\
Base Hidrográfica Oficial - PR & $1: 50.000^{* *}$ & COPEL/ITCG/INSTITUTO DAS ÁGUAS DO PR** \\
\hline Fontes: * Instituto de Terras, Cartografia e Geociências (ITCG), 2011; ** Instituto das Águas do PR, 2011.
\end{tabular}

Quanto a se trabalhar com escalas pequenas e diferentes, são estes os dados disponíveis, mesmo em outros suportes. A análise espacial tem a vantagem de evitar os erros de interpolação, comuns em meios físicos, e aumentar enormemente a precisão da observação humana.

\section{Análise espacial}

O aplicativo usado foi o ArcView 10.0. A caracterização das unidades foi realizada em duas etapas. A análise ecológica de reconhecimento foi feita a partir dos mapas em escala menor, considerando-se a interdependência dos elementos determinantes da complexidade ambiental (Figura 2). A análise nessa escala é fundamental para a caracterização ecológica mesmo quando se trabalha com áreas bastante pequenas, que exigem detalhamento em campo. Nestes casos, a análise de reconhecimento revela se se está trabalhando numa área que segue a regra desse ambiente ou numa de exceção, o que tem imensa repercussão ecológica.

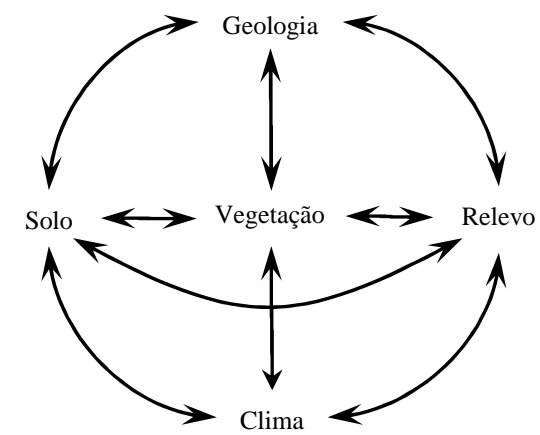

Figura 2. Fluxograma de interdependência dos processos ambientais.

Figure 2. Interdependency diagram of environmental process.

Os mapas digitais foram recortados usando-se o polígono retangular da área em estudo como molde/limites. Dessa base digital (temática e planialtimétrica) foram extraídas as feições e os atributos necessários para a análise ambiental da área: fisiografia, geologia, geomorfologia, clima, bacia hidrográfica, relevo, classe e textura de solo, vegetação original (domínio e formação), altitude, degradação e uso de solo.

Os recortes obtidos foram sobrepostos e fundidos num único arquivo, cuja tabela de atributos reuniu todas as informações dos arquivos de origem. O arquivo das árvores matrizes foi, então, adicionado e, para maior clareza dos mapas finais, todos os polígonos que não continham matrizes foram eliminados. Esse procedimento gerou o mapa Unidades Ecológicas. 
Além de gerar o mapa temático "Unidades Ecológicas (UEs)", com áreas homogêneas reunindo uma ou mais matrizes cada uma, esse arquivo vetorial permitiu a confecção de mapas temáticos de todos os atributos relacionados no banco de dados. Foram produzidos mapas das formações e grupos geológicos, relevo, classe e textura de solo, para melhor analisar a área. Cada um desses mapas revela singularidades ambientais que só poderiam ser conhecidas no mapa geral das UEs com a ajuda do banco de dados. Como informações complementares, foram acrescentados os mapas de hidrografia e estradas.

Devido às dimensões da área em estudo, optou-se por ter como produtos mapas na escala final de 1:200.000 (mapa de reconhecimento de média intensidade), que permitem avaliação qualitativa e semiquantitativa do solo, checagens de campo e correlações solo-paisagem (INSTITUTO BRASILEIRO DE GEOGRAFIA E ESTATÍSTICA (IBGE), 2007).

Para a análise ecológica mais detalhada, foi utilizado o mapa em escala 1:50.000. O mapa altimétrico com curvas de nível com equidistância de $20 \mathrm{~m}$ deu origem, por processamento digital, aos mapas de elevação, exposição e inclinação da vertente.

\section{RESULTADOS E DISCUSSÃO}

O processamento dos dados revelou ser a área (polígono retangular com 31 mil ha) homogênea para fisiografia (segundo planalto paranaense), bacia hidrográfica (Tibagi), clima (Cfb, Koeppen) (AYOADE, 1996), zona (Neotropical), domínio (Floresta Ombrófila Mista), formação (montana) e uso de solo (reflorestamento).

Apesar de ser considerada domínio da Floresta Ombrófila Mista nos mapas oficiais (suportes analógicos ou digitais), as observações em campo revelaram ser esta uma região ecotonal. Até cerca de 700 m s.n.m.m., a presença de espécimes da Floresta Estacional Semidecidual é dominante. A espécie em estudo, no entanto, não ajuda a estabelecer limites fitogeográficos, uma vez que ocorre nessas duas unidades (CARVALHO, 2008). As matrizes estão localizadas em áreas de preservação permanente (APPs) e reserva legal, limitadas por extensas áreas de plantio de Eucalyptus spp. e Pinus spp.

Os demais atributos analisados - geologia, relevo, classe e textura de solo - apresentaram diferenças significativas. Pelo cruzamento desses dados, então, foram delineadas nove (9) zonas de conformidade, chamadas UEs, nomeadas de 'A' a 'I' (Tabela 2) (Figura 3). Vale ressaltar que as UEs não são formadas apenas por esses atributos abióticos, mas também pelos considerados homogêneos no primeiro parágrafo desta discussão. Assim, a UE 'A', por exemplo, onde estão as matrizes $10,13,14,18$, 19 e 20, está, teoricamente, no segundo planalto paranaense, na bacia hidrográfica do rio Tibagi, sob clima Cfb (Koeppen), em zona Neotropical, Floresta Ombrófila Mista Montana, em região com predomínio de reflorestamento, com origem geológica no Paleozoico/Permiano, Grupo Guatá Formação Rio Bonito [porção basal arenosa (Membro Triunfo) e porção superior de siltitos esverdeados (Membro Paraguaçu)], em terreno fortemente ondulado a montanhoso, onde prevalece Neossolo Litólico Eutrófico típico, com textura argilosa.

As demais unidades estão descritas nas tabelas 2 a 4 .

Tabela 2. Distribuição das matrizes nas áreas de homogeneidade ambiental (Unidades Ecológicas).

Table 2. Parents trees distribution in the homogeneous environmental areas (Ecological Units).

\begin{tabular}{lc}
\hline Unidade Ecológica & Matrizes \\
\hline A & $10,13,14,18,19$ e 20 \\
B & 6 \\
C & 5 e 7 \\
D & 2,3 e 4 \\
E & 1 e 17 \\
F & 15 \\
G & 16 \\
H & 9 \\
I & 8,11 e 12 \\
\hline
\end{tabular}

O delineamento das UEs, ao revelar as porções do terreno onde as condições ambientais são semelhantes, permite estabelecer áreas potenciais de crescimento e desenvolvimento de exemplares dessa 
espécie que, tendo teoricamente as mesmas características, também poderão servir como matrizes para coleta de sementes.

Por interessarem ao experimento apenas as características de onde estão estabelecidas as matrizes, com o delineamento das Unidades Ecológicas passou-se a se trabalhar somente com as áreas onde estão inseridos esses espécimes - uma área de 14.144,66 ha (Figura 3).

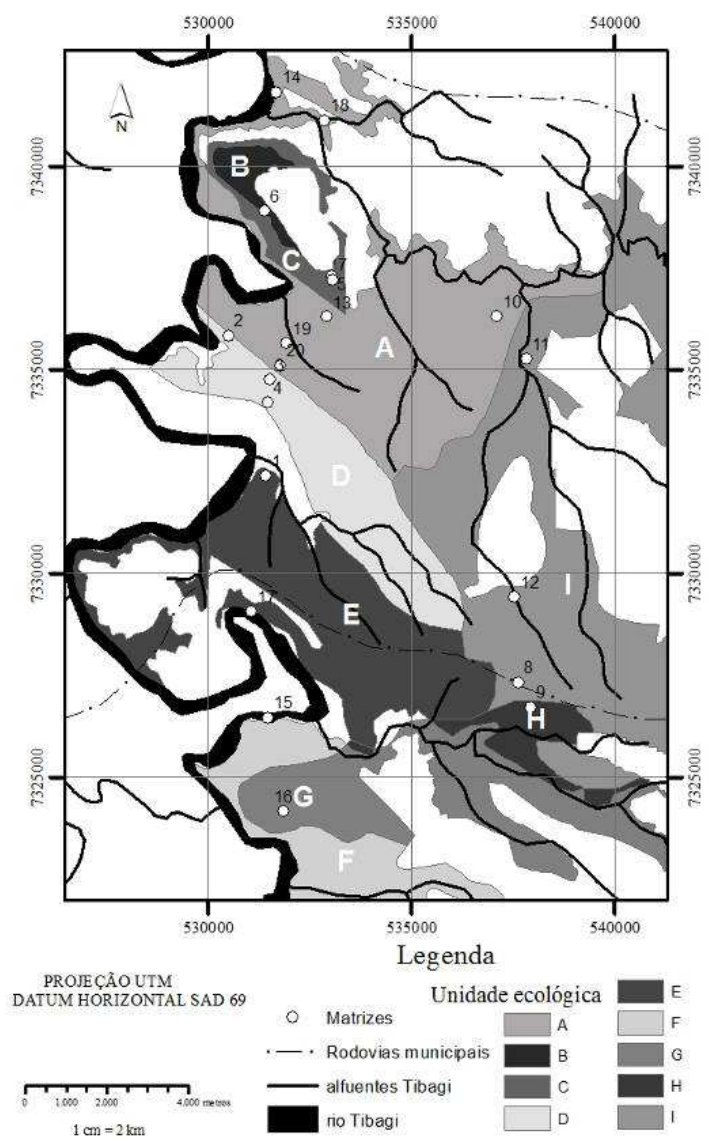

Figura 3. Mapa de distribuição de matrizes e Unidades Ecológicas.

Figure 3. Parent trees distribution and Ecological Units map.

A Unidade Ecológica com o maior número de matrizes é a 'A', 6 exemplares. Nas UEs 'D' e 'I' há 3 indivíduos cada. As UEs ' $C$ ' e ' $E$ ' têm duas matrizes cada, e nas demais áreas há apenas uma matriz em cada uma. Para facilitar a análise por propriedade, foram gerados, do arquivo UEs, mapas temáticos de geologia, relevo, classe e textura de solos (Figura 4).

Situada no Planalto de Ponta Grossa, a área em estudo está sobre rochas sedimentares do Paleozoico. Compõem o embasamento das Unidades Ecológicas o Grupo Itararé e as formações Rio Bonito, Irati e Serra Alta, dos Grupos Guatá e Passa Dois. Com idades variando entre 280 e 230 milhões de anos, o Grupo Itararé é o mais antigo, e as Formações Irati e Serra Altas as mais recentes. A Formação Rio Bonito tem idade estimada em 250 milhões de anos (Tabela 3, Figura 4a).

Os terrenos mais antigos estão em pouco menos de $18 \%$ da área. A Formação Rio Bonito predomina entre as feições e responde, assim como sua idade geológica, por $78 \%$ do espaço. As Formações Serra Alta e Irati somam juntas 3,45\% (Figura 4a).

A forte presença da Formação Rio Bonito faz com que predominem na região as formações com porção basal arenosa (Membro Triunfo) e porção superior de siltitos esverdeados (Membro Paraguaçu) (Tabela 3). Os diques de diabásio, muito presentes na região e facilmente identificados em campo, não aparecem nesses mapas devido à escala de trabalho. 
Tabela 3. Idades e formações geológicas presentes nas Unidades Ecológicas.

Table 3. Ages and geological formation present in the Ecological Units.

\begin{tabular}{|c|c|c|c|}
\hline $\begin{array}{l}\text { Unidade } \\
\text { ecológica }\end{array}$ & Idade geológica & Formação geológica & Descrição geológica \\
\hline A & Permiano & Rio Bonito & $\begin{array}{c}\text { Porção basal arenosa (Membro Triunfo) e porção } \\
\text { superior de siltitos esverdeados (Membro Paraguaçu) }\end{array}$ \\
\hline B & Permiano & Serra Alta & Lamitos e folhelhos cinza escuro esverdeados \\
\hline $\mathrm{C}$ & Permiano & Irati & $\begin{array}{l}\text { Argilitos e folhelhos pirobetuminosos cinza-escuro a } \\
\text { pretos, intercalações de lentes de calcário cinza-claro }\end{array}$ \\
\hline $\mathrm{D}$ & Permiano & Rio Bonito & $\begin{array}{l}\text { Porção basal arenosa (Membro Triunfo) e porção } \\
\text { superior de siltitos esverdeados (Membro Paraguaçu) }\end{array}$ \\
\hline $\mathrm{E}$ & Permiano & Rio Bonito & $\begin{array}{l}\text { Porção basal arenosa (Membro Triunfo) e porção } \\
\text { superior de siltitos esverdeados (Membro Paraguaçu) }\end{array}$ \\
\hline $\mathrm{F}$ & $\begin{array}{l}\text { Permo } \\
\text { Carbonífero }\end{array}$ & $\begin{array}{l}\text { Grupo Itararé } \\
\text { indiviso }\end{array}$ & $\begin{array}{l}\text { Conjunto heterogêneo de rochas sedimentares: } \\
\text { arenitos, siltitos, folhelhos, argilitos, diamictitos, } \\
\text { tilitos e ocasionalmente carvão }\end{array}$ \\
\hline G & $\begin{array}{l}\text { Permo } \\
\text { Carbonífero }\end{array}$ & $\begin{array}{l}\text { Grupo Itararé } \\
\text { indiviso }\end{array}$ & $\begin{array}{l}\text { Conjunto heterogêneo de rochas sedimentares: } \\
\text { arenitos, siltitos, folhelhos, argilitos, diamictitos, } \\
\text { tilitos e ocasionalmente carvão }\end{array}$ \\
\hline $\mathrm{H}$ & Permiano & Rio Bonito & $\begin{array}{l}\text { Porção basal arenosa (Membro Triunfo) e porção } \\
\text { superior de siltitos esverdeados (Membro Paraguaçu) }\end{array}$ \\
\hline I & Permiano & Rio Bonito & $\begin{array}{l}\text { Porção basal arenosa (Membro Triunfo) e porção } \\
\text { superior de siltitos esverdeados (Membro Paraguaçu) }\end{array}$ \\
\hline
\end{tabular}

Tabela 4. Descrição do relevo, classes e textura de solo por Unidade Ecológica.

Table 4. Relief, soil classes and texture description by Ecological Unit.

\begin{tabular}{|c|c|c|c|}
\hline $\begin{array}{l}\text { Unidade } \\
\text { ecológica }\end{array}$ & Relevo & Classes de solo & Textura \\
\hline A & $\begin{array}{c}\text { fortemente } \\
\text { ondulado/montanhoso }\end{array}$ & NEOSSOLO LITÓLICO Eutrófico típico & argilosa \\
\hline B & $\begin{array}{c}\text { fortemente } \\
\text { ondulado/montanhoso }\end{array}$ & NEOSSOLO LITÓLICO Eutrófico típico & argilosa \\
\hline $\mathrm{C}$ & $\begin{array}{c}\text { fortemente } \\
\text { ondulado/montanhoso }\end{array}$ & NEOSSOLO LITÓLICO Eutrófico típico & argilosa \\
\hline $\mathrm{D}$ & $\begin{array}{l}\text { montanhoso/ } \\
\text { fortemente ondulado }\end{array}$ & $\begin{array}{c}\text { Associação NEOSSOLO LITÓLICO Eutrófico típico + NEOSSOLO } \\
\text { Eutrófico chernossólico + NITOSSOLO VERMELHO Distroférrico } \\
\text { típico }\end{array}$ & argilosa \\
\hline $\mathrm{E}$ & ondulado & $\begin{array}{l}\text { Associação ARGISSOLO VERMELHO-AMARELO Distrófico } \\
\text { típico + NEOSSOLO LITÓLICO Distrófico típico }\end{array}$ & $\begin{array}{l}\text { média/ } \\
\text { argilosa }\end{array}$ \\
\hline $\mathrm{F}$ & $\begin{array}{l}\text { suave ondulado/ } \\
\text { ondulado }\end{array}$ & $\begin{array}{l}\text { Associação ARGISSOLO VERMELHO-AMARELO Distrófico } \\
\text { abrúptico, álico + NEOSSOLO LITÓLICO Eutrófico típico + } \\
\text { ALISSOLO CRÔMICO Argilúvico abrúptico }\end{array}$ & $\begin{array}{l}\text { média/ } \\
\text { argilosa }\end{array}$ \\
\hline G & $\begin{array}{l}\text { suave ondulado/ } \\
\text { ondulado }\end{array}$ & ARGISSOLO VERMELHO-AMARELO Distrófico típico, álico & $\begin{array}{l}\text { arenosa/ } \\
\text { média }\end{array}$ \\
\hline $\mathrm{H}$ & $\begin{array}{l}\text { suave ondulado/ } \\
\text { ondulado }\end{array}$ & ARGISSOLO VERMELHO-AMARELO Distrófico típico, álico & $\begin{array}{l}\text { arenosa/ } \\
\text { média }\end{array}$ \\
\hline I & suave ondulado & LATOSSOLO VERMELHO Distrófico típico, álico & argilosa \\
\hline
\end{tabular}

Resultado do tectonismo e do intemperismo das rochas, o relevo tem influência direta na gênese dos solos. Segundo EMBRAPA (1979), o relevo é considerado plano quando a declividade está entre 0 e $3 \%$. Entre 3 e $8 \%$, é suave ondulado. De 8 a $20 \%$ é denominado ondulado. De 20 a $45 \%$ é classificado como fortemente ondulado e acima de $45 \%$, montanhoso (Figura $4 b$ ).

O relevo fortemente ondulado e montanhoso está presente em pouco mais de $36 \%$ da área. As porções de terreno com relevo ondulado e com a associação deste com suave ondulado somam também pouco mais de $36 \%$, revelando uma paisagem bastante movimentada. O relevo suave ondulado ocupa $27 \%$ das Unidades Ecológicas.

Os Neossolos estão associados a relevos fortemente ondulados e montanhosos (Unidades 'A', 'B', ' $C$ ' e 'D') e os Latossolos a relevos planos e suave ondulados (UE 'I') (Tabela 4). Assim, os percentuais de ocorrência para as feições de relevo vão se repetir nos obtidos para os solos predominantes nas Unidades. 

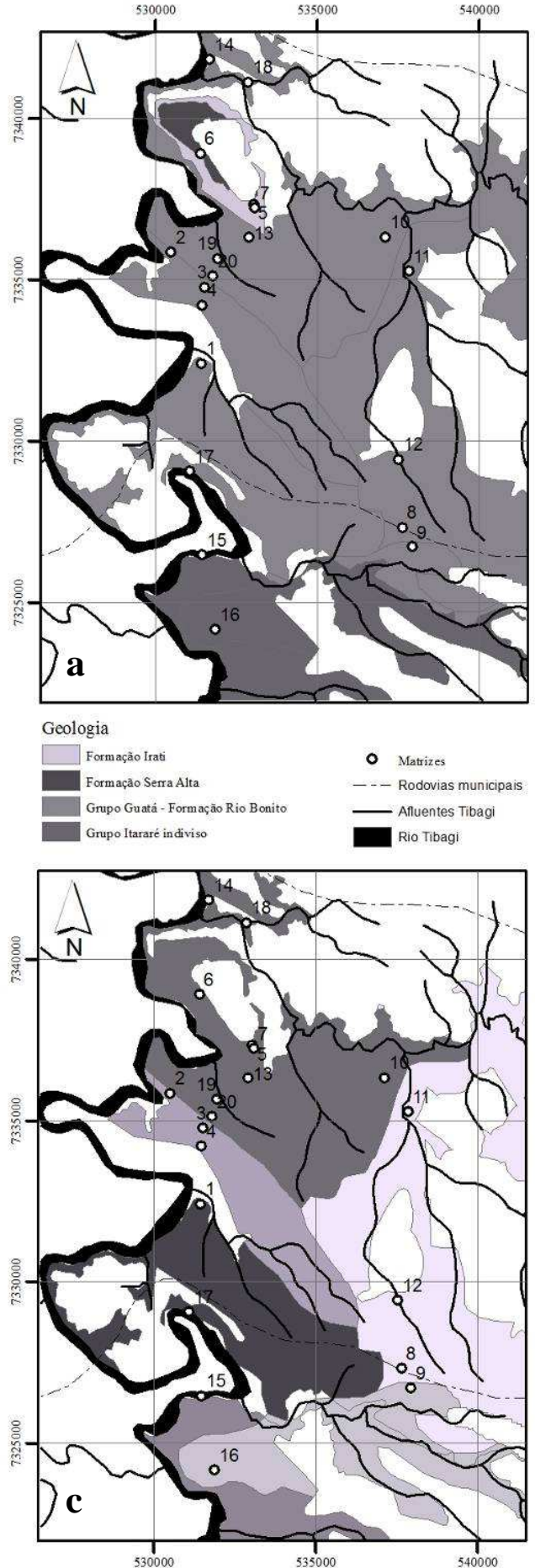

Classe de solo

Classe de solo

ARGISSOLO NERMEL HO-AMAREL O Distrófico tipico

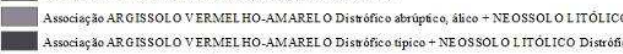

- Assodico VeOsolo

$\square$ LAIOSSOLO VERMEL HO Distrófico tipice, alico

Figura 4. Mapas de grupos e formações geológicas, relevo, classes e textura de solo.

Figure 4. Geological groups and formations, relief, soil classes and texture maps. 
Nas Unidades 'A', 'B' e 'C' predomina Neossolo Litólico Eutrófico típico (Tabela 4), classe com o maior número de matrizes e que responde por pouco mais de $26 \%$ dos solos da área. Se considerada ainda a associação de solos onde prevalecem os Neossolos Eutróficos, UE 'D', este percentual sobe para pouco mais de 36\%. Mesmo sendo rasos, sobre esses solos férteis estão 9 matrizes, 45\% do total, corroborando a preferência da espécie por solos de fertilidade elevada e sua fama de indicadora de bons solos para a agricultura (CARVALHO, 2008) (Figura 4c).

Os Latossolos prevalecem numa área de 3.817 ha, $27 \%$ do total. Estes são solos muito intemperizados, profundos e com boa drenagem, mas com baixa fertilidade natural. Neles estão localizadas 3 matrizes (Figura 4c). Nessa escala de trabalho não é possível dizer se as matrizes estão sobre alguma mancha de solo mais fértil ou se, confirmando a plasticidade da espécie, estão sobre solos distróficos. $\mathrm{O}$ baixo número de matrizes nessa condição pode ser atribuído, ainda, ao fato de esta ser, pelo relevo e profundidade de solo, a unidade mais aproveitada para plantios florestais.

Devido à formação geológica local, os solos são majoritariamente argilosos. Essa textura predomina em pouco mais de $60 \%$ da área. Em segundo lugar vem a textura intermediária média/argilosa, com $23 \%$. A textura arenosa/média é dominante mais ao sul, em 13,67\% da área, nos solos sob influência do Grupo Itararé (Figura 4d).

Os dados espaciais públicos, no entanto, permitem mais que uma análise ecológica de reconhecimento. Já estão disponíveis dados planialtimétricos em escala 1:50.000 para todo o estado do Paraná. A partir deles é possível obter o Modelo Digital do Terreno (MDT), estabelecendo, nos limites da escala, elevação (altitude em m s.n.m.m.), exposição do terreno e inclinação da vertente.

Os dados sobre degradação são de 1995 (mapa elaborado pela Secretaria Estadual do Meio Ambiente (SEMA), disponível em ITCG, 2011) e, para evitar maior segmentação da área, também foram considerados por matriz (Figura 5d e Tabela 5).

Tabela 5. Atributos de posicionamento e degradação ambiental por árvore matriz.

Table 5. Positioning attributes and environmental degradation by parent tree.

\begin{tabular}{lcccc}
\hline Matriz & Elevação $(\mathbf{m})$ & Exposição & Inclinação da vertente (\%) & Degradação \\
\hline 1 & 610 & Leste & $3-8$ & Média \\
2 & 650 & Sudoeste & $20-45$ & Média \\
3 & 670 & Nordeste & $8-20$ & Média \\
4 & 680 & Sudeste & $8-20$ & Média \\
5 & 650 & Leste & $20-45$ & Média \\
6 & Sudoeste & $3-8$ & Média \\
7 & Plano & $0-3$ & Média \\
8 & 640 & Sudoeste & $8-20$ & Fraca \\
9 & 760 & Norte & $0-3$ & Fraca \\
10 & 740 & Leste & $3-8$ & Média \\
11 & 705 & Plano & $0-3$ & Fraca \\
12 & 660 & Nordeste & $8-20$ & Fraca \\
13 & 730 & Sul & $0-3$ & Média \\
14 & 680 & Plano & $0-3$ & Forte \\
15 & 520 & Plano & $0-3$ & Média \\
16 & 600 & Sudoeste & $0-3$ & Média \\
17 & 700 & Sudoeste & $0-3$ & Média \\
18 & 600 & Oeste & $20-45$ & Forte \\
19 & 520 & Norte & $3-8$ & Média \\
20 & 640 & Plano & $0-3$ & Média \\
\hline
\end{tabular}

As árvores em estudo estão predominantemente abaixo dos $700 \mathrm{~m}$ de altitude, o que pode ser explicado por essa espécie nativa estar presente principalmente em áreas de preservação permanente. Nessa região, as porções mais elevadas do terreno $(800,900 \mathrm{~m})$ são as mais planas (Figura 5a), ocupadas principalmente por plantios florestais. 


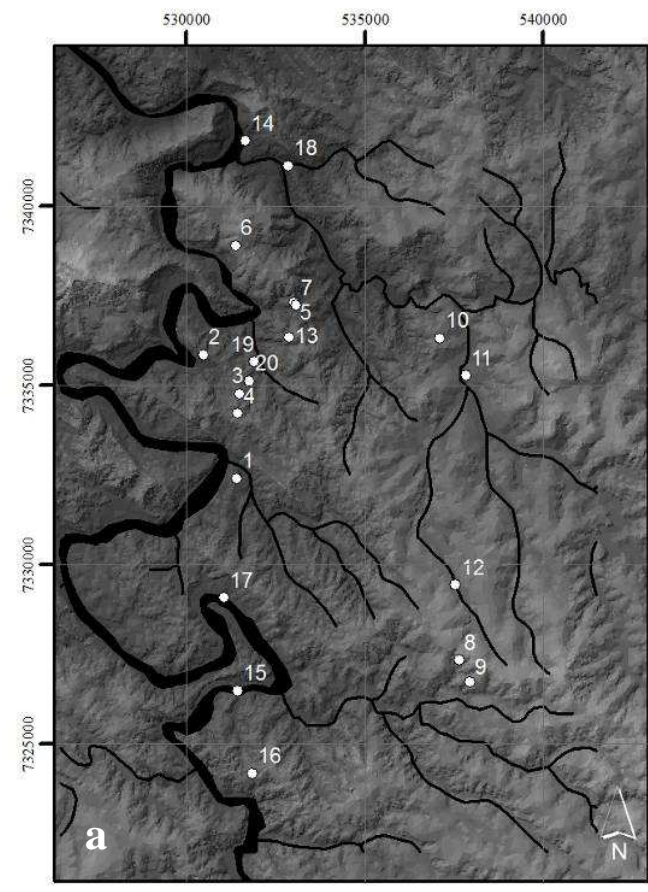

Elevação (m) $\quad 840-860 \quad 740-760 \quad 640-660 \square 540-560$

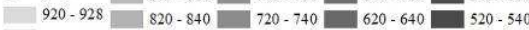

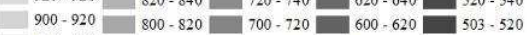
$\begin{array}{r}880-900 \square 780-800 \square \\ 860-880 \square \\ \hline\end{array}$

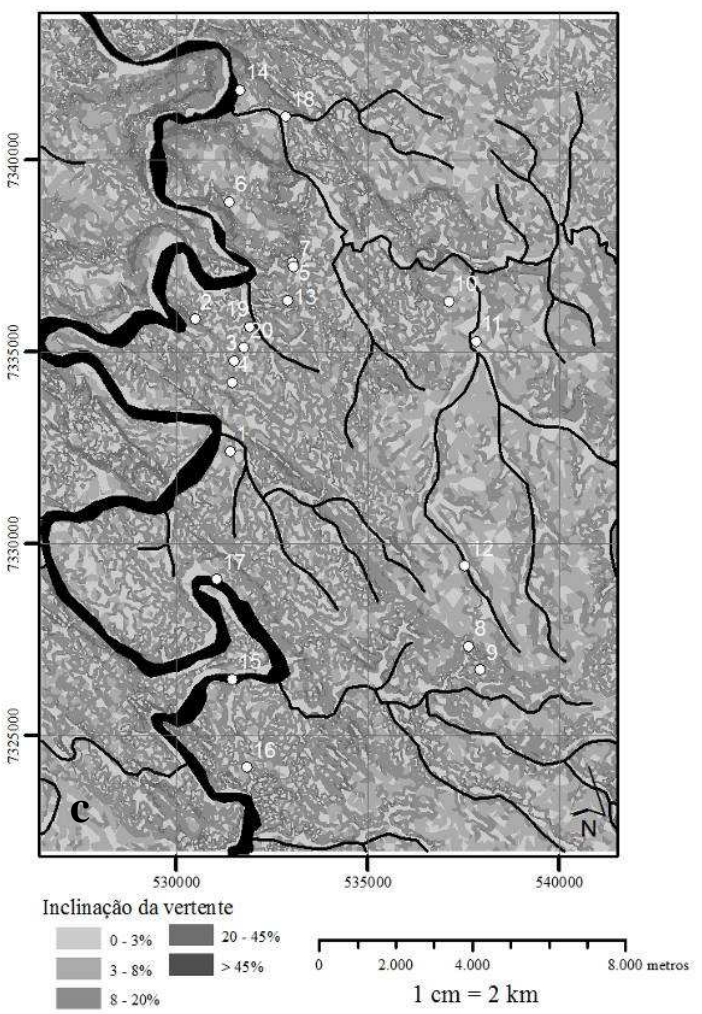

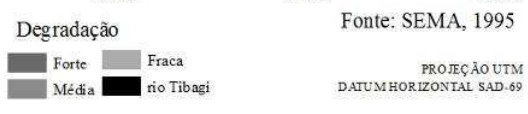
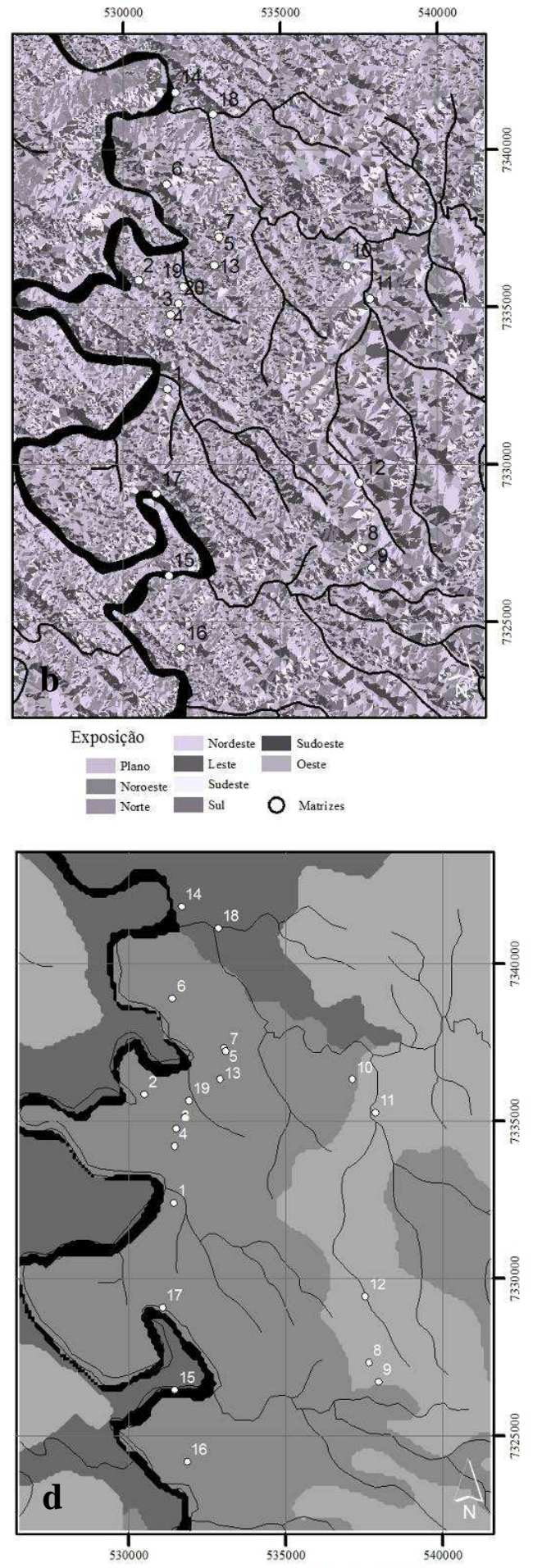

Figura 5. Mapas de elevação, exposição, inclinação da vertente e degradação. Figure 5. Elevation, aspect, slope and degradation maps. 
Apesar de tentador, não é possível inferir aqui as preferências da espécie por face de exposição e declividade, para o que seria necessário outro delineamento de estudo. Pode-se determinar, no entanto, a situação desses espécimes em particular em relação a esses atributos. Em campo, observou-se que as árvores escolhidas ocupam principalmente os topos de morros e as bases das vertentes (terço inferior), porções mais aplainadas do terreno, mesmo quando a região em torno é bastante acidentada. A análise espacial realizada confirmou essa tendência, indicando que a maior parte das matrizes ocorre em inclinação de 0-3\% (Figura 5c).

A degradação ambiental, especialmente do solo, por práticas agrícolas equivocadas, é acentuada na região (Figura 5d), mas as matrizes estão majoritariamente em áreas com degradação média e fraca. Por dificultar sua exploração, o relevo acidentado foi, até aqui, o protetor das florestas. Mas é esse mesmo relevo que torna a área interessante para a construção da Usina Hidrelétrica Mauá. O impacto da formação do lago da represa (cota máxima de enchimento: $635 \mathrm{~m}$ ) será alto sobre esses remanescentes florestais.

Nas representações do terreno feitas a partir das curvas de nível, é possível identificar alguns diques de diabásio (porções mais elevadas, retilíneas, principalmente na direção SE-NW) (Figura 5, particularmente $5 b$ - Exposição).

\section{CONCLUSÕES}

- O tipo de dado disponibilizado agora ao público em geral traz, muitas vezes, informações não observáveis em campo ou por imagens de satélite, refinando o produto final (principalmente mapas temáticos). Com tal quantidade de dados à disposição, o pesquisador tem liberdade para estabelecer unidades de convergência de atributos segundo suas necessidades. Conforme o experimento, a análise desse tipo de dado, por meio de SIG, pode constituir a caracterização ou a pré-caracterização de uma área, contribuindo inclusive no delineamento do estudo.

- Com a possibilidade de cruzamento desse volume de dados, deixa-se, também, a prática, muito comum, de se analisar áreas de interesse a partir de divisões geopolíticas e passa-se a se considerar os limites naturais na definição de características ambientais.

- Com os dados se tornando públicos, é preciso que também o acesso aos softwares o seja. Esse caminho já está sendo aberto. Estão surgindo softwares livres ou a baixo custo no mercado, com boa capacidade de processamento, conforme o estudo realizado por Couto Júnior e Carvalho (2008).

- Especificamente no caso em estudo, a técnica permite, de maneira confiável, inferir sobre a plasticidade de $P$. dioica, notadamente em regiões em que a cartografia registra a heterogeneidade geológica em escalas médias a grandes. Generalizando para outras espécies e formações vegetais, e confiando que o futuro garanta acesso cada vez menos restrito a dados cada vez mais detalhados, a distribuição de espécies poderá deixar de ser uma informação meramente descritiva para se tornar conhecimento de fato. A repercussão disso na análise biogeográfica pode ser definitiva.

\section{REFERÊNCIAS}

AYOADE, J. O. Introdução à climatologia para os trópicos. Rio de Janeiro: Editora Bertrand Brasil S.A., 1996. 332 p.

BACKES, P.; IRGANG, B. Árvores do sul: guia de identificação \& interesse ecológico. Instituto Souza Cruz, 2002. 325 p.

BIGARELLA, J. J. Estrutura e origem das paisagens tropicais e subtropicais. v. 3 Florianópolis: Editora UFSC, 2003. p. 877 - 1436.

CÂMARA, G.; MEDEIROS, J. S. Princípios básicos em geoprocessamento. In: ASSAD, E. D.; SANO, E. E. Sistema de informações geográficas: aplicações na agricultura. 2. ed. Brasília: Embrapa - SPI/ Embrapa - CPAC, 1998. p. 3 - 11.

CARVALHO, P. E. R. Espécies arbóreas brasileiras. Brasília: Embrapa Informação Tecnológica; Colombo, PR: Embrapa Florestas, 2008. 1039 p. 
CHRISTOFOLETTI, A. Geomorfologia. 2. ed. São Paulo: Edgar Blücher, 1980. 188 p.

COSTA, N.; XAVIER-DA-SILVA, J. Geoprocessamento aplicado à criação de planos de manejo: o caso do Parque Estadual da Pedra Branca, RJ. In: XAVIER-DA-SILVA, J.; ZAIDAN, R. T. Geoprocessamento e análise ambiental: aplicações. Rio de Janeiro: Bertrand Brasil, 2004. p. 67 - 114.

COUTO JÚNIOR, A. C. S.; CARVALHO, L. M. T. Estudo das possibilidades de uso de software livre de SIG para o ensino nos cursos de Engenharia Florestal. In: SEMINÁRIO DE ATUALIZAÇÃO EM SENSORIAMENTO REMOTO E SISTEMAS DE INFORMAÇÕES GEOGRÁFICAS APLICADOS À ENGENHARIA FLORESTA, 8., 2008. Anais do... Curitiba: FUPEF, 2008. 1 CD-ROM.

EMPRESA BRASILEIRA DE PESQUISA AGROPECUÁRIA (EMBRAPA). Manual de métodos de análise de solo. Rio de Janeiro: SNLCS, 1979, não paginado.

. Sistema brasileiro de classificação de solos. 2. ed. Rio de Janeiro: Embrapa Solos, 2006. 306 p.

GUIMARÃES, G. R.; MELO, M. S. de; GIANNINI, P. C. F.; MELEK, P. R. Geologia. In: MELO, M. S. de; MORO, R. S.; GUIMARÃeS, G. R. Patrimônio natural dos Campos Gerais do Paraná. Ponta Grossa: Editora UEPG, 2007. 230 p.

INSTITUTO BRASILEIRO DE GEOGRAFIA E ESTATÍSTICA (IBGE). Manual técnico de pedologia. 2. ed. Rio de Janeiro, 2007. 316 p.

INSTITUTO AGRONÔMICO DO ESTADO DO PARANÁ (IAPAR). Médias pluviométricas históricas - município de Telêmaco Borba. Disponível em: <http://www.iapar.br/arquivos/Image/ monitoramento/Medias_Historicas/Telemaco_Borba.htm>. Acesso em 26/09/2011.

INSTITUTO DAS ÁGUAS DO PARANÁ. Base hidrográfica oficial do Paraná. Disponível em: <http://www.aguasparana.pr.gov.br> ou <http://www.suderhsa.pr.gov.br>. Acesso em 20/09/2011.

INSTITUTO DE TERRAS, CARTOGRAFIA E GEOCIÊNCIAS (ITCG). Produtos cartográficos. Disponível em: <http://www.itcg.pr.gov.br/modules/conteudo/conteudo.php?conteudo=47> e <http://www.itcg.pr.gov.br/modules/conteudo/conteudo.php?conteudo=51>. Acesso em 30/08/2011.

LEPSCH, I. F. Formação e conservação dos solos. São Paulo: Oficina de Textos, 2002. 178 p.

LOPES, J. Os movimentos coletivos dos solos e a evolução das encostas naturais nas regiões tropicais e subtropicais úmidas. Boletim Paranaense de Geociências, América do Norte, 49, 08/2004. Disponível em: <http://ojs.c3sl.ufpr.br/ojs2/index.php/geociencias/article/view/4130/3329>. Acesso em 22/08/2011.

MANTESSO NETO, V.; BARTORELLI, A.; CARNEIRO, C. D. R.; BRITO NEVES, B. B. Geologia do continente sul-americano: evolução da obra de Fernando Flávio Marques de Almeida. 1. ed. São Paulo, Beca, 2004. 573 p.

MINERAIS DO PARANÁ (MINEROPAR). Atlas geológico do estado do Paraná, Curitiba, 2001. 125 p.

REITZ, R.; KLEIN, R. M.; REIS, A. Projeto madeira do Rio Grande do Sul. Anais Botânicos do Herbário "Barbosa Rodrigues", Sellowia nos 34 - 35. Itajaí, SC, 1983. 525 p.

SCHAETZL, R. J.; ANDERSON, S. Soils - genesis and geomorphology. Cambridge University Press, UK, 2005. $833 \mathrm{p}$.

VEIGA, T. C.; XAVIER-DA-SILVA, J. Geoprocessamento aplicado à identificação de áreas potenciais para atividades turísticas: o caso do município de Macaé - RJ. In XAVIER-DA-SILVA, J.; ZAIDAN, R. T. Geoprocessamento e análise ambiental: aplicações. Rio de Janeiro: Bertrand Brasil, 2004. p. 179 - 215. 